\title{
In Memoriam Enrique García Díez
}

Kevin Power

Universidad de Alicante

To say good-bye is a graceless act. Grief is an intimate and private act. And there are, of course, no words for loss. Everything falls into silence... Enrique García Díez was a close friend and life provides very few such occasions of friendship. The time for anecdotes and memories may come. There are no beginnings, no ends, just torn addresses, and the endless sweeping movement of the river. The qualities of the man are numerous and valuable to us all: an out-going impulse towards others, a generosity of spirit, an ability to bring alive the present, an easy open laughter, an insatiable curiosity. They are more than I can say, or even hope to hold in these empty shell. His academic distinctions are the steps in a career. They have their place and will come to speak for themselves. His chair of Literatura Norteamericana was the first to be dedicated exclusively to American Studies in Spain. This is as it should have been since Enrique García Díez had a genuine passion for American Literature, especially for Faulkner and the contemporary novel. He was drawn to those texts, as his friend John Barth says in "Literature of Exhaustion," that not many people can do, the kind that require expertise and artistry as well as bright aesthetic ideas and/or inspiration. $\mathrm{He}$ enjoyed the contrivances of literature and understood that there is no longer any point in hiding behind the walls of self-contained disciplines, that poetics is giving way to general aesthetics, that a consideration of the novel is moving easily towards film, etc. This is a world of changing values, of shifting sands, and finally of wretchedly cruel tides. We look for a final phrase. There are none. Snow to darkness. 